\title{
Correlation of the mutual diffusion coefficients of binary liquid mixtures
}

\author{
Yu-Du Hsu, Yan-Ping Chen * \\ Department of Chemical Engineering, National Taiwan University, Taipei, Taiwan \\ Received 23 February 1998; accepted 15 June 1998
}

\begin{abstract}
A correlative UNIDIF model for the mutual diffusion coefficients of binary liquid mixtures is developed using statistical thermodynamics and the absolute reaction rate theory. In this model, a mole fraction average of the logarithm of the pure-component limiting diffusion coefficients is taken as a reference term. The model expresses the excess part of the diffusion coefficient relative to this reference term in a form similar to that of a UNIQUAC equation which comprises two parts due to the combinatorial and residual contributions. The combinatorial part depends on the molecular sizes and shapes. The residual part includes two binary interaction parameters, which are obtained from data regression, for each binary mixture. Mutual diffusion coefficients of nonpolar + nonpolar, nonpolar + polar and polar + polar fluid mixtures are correlated in this study. Optimal binary interaction parameters are presented. Correlation results using the UNIDIF model for mutual diffusion coefficient are satisfactory and are superior to those from other methods. (C) 1998 Elsevier Science B.V. All rights reserved.
\end{abstract}

Keywords: Method of calculation; Diffusion coefficient; Mixture

\section{Introduction}

Transport properties, such as the viscosity, thermal conductivity and diffusion coefficient, are essential to the design of chemical processes and equipment involving fluid flow, heat and mass transfer, and chemical reactions. Although viscosity and thermal conductivity of liquid mixtures have been correlated using statistical thermodynamics and local composition concepts [1,2], a similar method for the treatment of liquid mutual diffusion coefficients has yet not been presented. Simple equations are not adequate to express the concentration dependence of liquid mutual diffusion coefficients. Correlation of the mutual diffusion coefficients can be presented using the hydrodynamic

\footnotetext{
${ }^{*}$ Corresponding author. Tel.: +886-2363-5230; fax: +886-2362-3040 
or absolute reaction rate theory. A review of liquid diffusion of non-electrolyte solutions has been presented by Ghai et al. [3]. A recent discussion for the estimation of diffusion coefficients of dense fluids on binary and multicomponent mixtures has been shown by Riazi and Whitson [4]. Most correlation equations express the mutual diffusion coefficient as the product of an ad hoc compositional average of the limiting diffusion coefficients and a thermodynamic factor, which contains the composition dependence of the activity. The thermodynamic factor is calculated from an activity coefficient model where the optimal binary interaction parameters are obtained from data regression. Siddiqi and Lucas [5] have compared various calculation methods using the NRTL model. They showed satisfactory results for nonpolar liquid mixtures, but larger deviations for polar systems. Cussler [6] proposed the cluster diffusion model and suggested a mutual diffusion correlation equation with two empirical parameters for a binary system. Further application of the cluster diffusion model has been presented by Cullinan [7] and Rollins and Knaebel [8]. Recently, Pertler et al. [9] reviewed various correlation equations for mutual diffusion coefficient and compared them for the binary mixtures which may have liquid phase separation.

Cao et al. [1] developed a statistical thermodynamics model for the viscosities of liquid mixtures. On the basis of the lattice theory, they started from the partition function and expressed the potential energy function by a local composition equation. They also applied the reaction rate theory [10] to express the frequency of molecular movement. The kinematic viscosity was finally written in a local composition form with two interaction parameters for each binary system. A method similar to that of Cao et al. [1] is employed for mutual diffusion coefficients of binary liquid mixtures in this study. The mutual diffusion coefficients are written also in a local composition form with combinatorial and residual contributions. Molecular size, shape and interaction effects are included in this correlation equation. This equation is then applied in calculating the mutual diffusion coefficients of nonpolar and polar binary mixtures. Correlation results and comparisons with other methods are presented in this study.

\section{Development of the mutual diffusion coefficient model}

Cao et al. [1] developed a statistical thermodynamics model for the viscosity of liquid mixtures. A similar approach is applied here to develop a mutual diffusion coefficient model. According to the lattice theory [11], the partition function of a liquid mixture is written as:

$$
\Omega=\Omega^{\mathrm{s}} \prod_{i=1}^{n}\left(\frac{2 \pi m_{i} k T}{h^{2}}\right)^{3 N_{i} / 2} \frac{\omega_{i}}{\omega_{i}^{\mathrm{s}}} \exp \left(-\frac{U_{0 i}}{k T}\right)
$$

where $U_{0 i}$ is the potential energy of lattice $i$ in a mixture, $n$ is the number of components in a mixture, $N_{i}$ is the number of molecules in component $i, \omega$ is the number of configurations of a lattice, and the superscript s represents the boundary condition of a Starveman's model. $U_{0 i}$ is the potential energy of a lattice in a mixture, and is expressed by a local composition model:

$$
-U_{0 i}=\frac{z q_{i} N_{i}}{2} \sum_{j=1}^{n} U_{j i} \theta_{j i}
$$


The local composition parameter $\theta_{j i}$ is approximated according to the equation of Abrams and Prausnitz [12]:

$$
\theta_{j i}=\frac{\theta_{j} \tau_{j i}}{\sum_{l=1}^{n} \theta_{l} \tau_{l i}}
$$

where $\theta_{j}$ is the average fraction of the surface area $q_{j}$ of component $j$ :

$$
\theta_{j}=\frac{x_{j} q_{j}}{\sum_{l=1}^{n} x_{l} q_{l}}
$$

The interaction parameter $\tau_{j i}$ in Eq. (3) is written as a Boltzmann factor of the binary interaction energy $a_{j i}$ and the coordination number $z$ :

$$
\begin{aligned}
& \tau_{j i}=\exp \left(-\frac{a_{j i}}{T}\right) \\
& a_{j i}=\frac{z}{2 k}\left(U_{j i}-U_{i i}\right)
\end{aligned}
$$

The absolute reaction rate theory [10] has been used to describe the transport properties of fluid mixtures. According to this theory, a molecule traveling between two neighboring equilibrium states has to overcome an energy barrier. The frequency of movement in a fluid mixture is expressed as:

$$
k_{a m}=\prod_{i=1}^{n}\left(\frac{k T}{2 \pi m_{i}}\right)^{x_{i} / 2} \exp \left(\frac{z}{2 k T} \sum_{i=1}^{n} x_{i} q_{i} \sum_{j=1}^{n} U_{j i} \theta_{j i}\right)
$$

\begin{tabular}{|c|c|c|}
\hline Equations & Equation names & References \\
\hline$D_{12}=\left(x_{1} D_{2}^{0}+x_{2} D_{1}^{0}\right)$ & Geet-Adamson & [15] \\
\hline$D_{12}=\left(x_{1} D_{2}^{0}+x_{2} D_{1}^{0}\right) \times\left(\left(\operatorname{dln} a_{1}\right) /\left(\operatorname{dln} x_{1}\right)\right)$ & Modified Darken & {$[16]$} \\
\hline$D_{12}=\left(D_{2}^{0}\right)^{x_{1}}\left(D_{1}^{0}\right)^{x_{2}} \times\left(\left(\mathrm{d} \ln a_{1}\right) /\left(\mathrm{d} \ln x_{1}\right)\right)$ & Vignes & {$[17]$} \\
\hline$D_{12}=(1) /\left(\eta_{m}\right)\left(x_{1} \eta_{1} D_{2}^{0}+x_{2} \eta_{2} D_{1}^{0}\right) \times\left(\left(\operatorname{dln} a_{1}\right) /\left(\operatorname{dln} x_{1}\right)\right)$ & Carman-Stein & {$[18]$} \\
\hline$D_{12}=(1) /\left(\eta_{m}\right)\left(n_{1} D_{2}^{0}\right)^{x_{1}}\left(\eta_{2} D_{1}^{0}\right)^{x_{2}} \times\left(\left(\operatorname{dln} a_{1}\right) /\left(\operatorname{dln} x_{1}\right)\right)$ & Leffler-Cullinan & [19] \\
\hline $\begin{array}{l}D_{12}=D_{0}\left\{1+C \times\left[(1) /\left(x_{1} x_{2}\right)\left(\left(\operatorname{dln} x_{1}\right) /\left(\operatorname{dln} a_{1}\right)-1\right)\right]^{b}\right\}^{-0.5} ; b \cong 1.23 \\
C \cong 0.17, D_{0}=\text { reference diffusion coefficient }\end{array}$ & Guerkan & {$[20]$} \\
\hline$D_{12}=(k T) /\left(2 \pi \eta_{m} V_{m}^{1 / 3}\right)\left[1+(1) /\left(2 \pi x_{1} x_{2}\right)\left(\left(\mathrm{d} \ln x_{1}\right) /\left(\mathrm{d} \ln a_{1}\right)-1\right)\right]^{-0.5}$ & Cullinan 1 & {$[7,8]$} \\
\hline $\begin{array}{l}D_{12}=\sqrt{f_{12}^{0}} D_{12}^{0}\left(\eta_{2}\right) /\left(\eta_{m}\right)\left(V_{2}^{1 / 3}\right) /\left(V_{m}^{1 / 3}\right)\left[1+(1) /\left(2 \pi x_{1} x_{2}\right)\left(\left(\mathrm{d} \ln x_{1}\right) /\right.\right. \\
\left.\left.\left(\mathrm{d} \ln a_{1}\right)-1\right)\right]^{-0.5} ; D_{12}^{0}=\text { limiting diffusion coefficient, } f_{12}^{0}=1-(1) / \\
(2 \pi) \lim _{x_{1} \rightarrow 0}\left(\mathrm{~d} \alpha_{12}\right) /\left(\mathrm{d} x_{1}\right), \text { and } \alpha_{12}=\left(\mathrm{d} \ln a_{1}\right) /\left(\mathrm{d} \ln x_{1}\right)\end{array}$ & Cullinan 2 & [8] \\
\hline
\end{tabular}

According to the absolute reaction rate theory [10], the diffusion coefficient is proportional to the product of the frequency of movement $\left(k_{a}\right)$ and the square of the distance between two equilibrium

Table 1

Correlative equations for the mutual diffusion coefficients of binary mixtures 
Table 2

Calculation results of the mutual diffusion coefficients of binary liquid mixtures

\begin{tabular}{|c|c|c|c|c|c|c|c|c|c|c|}
\hline \multirow{3}{*}{$\begin{array}{l}\text { System (component } \\
1+\text { component } 2 \text { ) }\end{array}$} & \multirow{3}{*}{$\begin{array}{l}\text { No. of } \\
\text { data } \\
\text { points }\end{array}$} & \multirow{3}{*}{$\begin{array}{l}\text { Temp. } \\
\text { range }(\mathrm{K})\end{array}$} & \multicolumn{2}{|c|}{ UNIDIF parameters (K) } & \multicolumn{5}{|c|}{$\operatorname{AAD}(\%)^{\mathrm{a}}$} & \multirow[t]{3}{*}{ References } \\
\hline & & & \multirow[t]{2}{*}{$a_{21}$} & \multirow[t]{2}{*}{$a_{12}$} & \multicolumn{2}{|c|}{ Modified darken } & \multicolumn{2}{|l|}{ Vignes } & \multirow[t]{2}{*}{ UNIDIF } & \\
\hline & & & & & NRTL & UNIQUAC & NRTL & UNIQUAC & & \\
\hline \multicolumn{11}{|l|}{ Normal alkanes } \\
\hline$n$-Hexane $+n$-dodecane & 30 & $\begin{array}{l}298.15- \\
308.15\end{array}$ & 0 & 0 & 3.6 & 8.3 & 1.4 & 5.8 & 1 & [21-23] \\
\hline$n$-Octane $+n$-dodecane & 21 & $\begin{array}{l}298.15- \\
333.15\end{array}$ & 0 & 0 & 1.9 & 4.2 & 0.9 & 3.1 & 0.6 & [15] \\
\hline$n$-Heptane $+n$-decane & 21 & 298.15 & 0 & 0 & 1.5 & 1.3 & 2.3 & 1.4 & 2.8 & [24] \\
\hline$n$-Heptane $+n$-dodecane & 20 & 298.15 & 0 & 0 & 6.5 & 10.6 & 3.9 & 7.8 & 2.6 & [24] \\
\hline$n$-Heptane $+n$-hexadecane & 7 & 298.25 & 0 & 0 & 6 & 14.7 & 1.2 & 9 & 2 & {$[21,22]$} \\
\hline$n$-Hexane $+n$-heptane & 25 & $\begin{array}{l}300.00- \\
328.00\end{array}$ & 0 & 0 & 0.6 & 0.6 & 0.6 & 0.6 & 0.6 & {$[25]$} \\
\hline$n$-Heptane $+n$-octane & 25 & $\begin{array}{l}293.00- \\
343.00\end{array}$ & 0 & 0 & 0.2 & 0.3 & 0.2 & 0.2 & 0.2 & [25] \\
\hline$n$-Heptane $+n$-tetradecane & 23 & 298.15 & 0 & 0 & 8.5 & 15.7 & 3.5 & 10.4 & 1.9 & [24] \\
\hline $\begin{array}{l}n \text {-Dodecane }+ \\
n \text {-hexadecane }\end{array}$ & 9 & 298.15 & 0 & 0 & 1.7 & 2.4 & 0.6 & 1.1 & 0.4 & [23] \\
\hline$n$-Hexane $+n$-hexadecane & 8 & 298.25 & 0 & 0 & 7.8 & 21.3 & 2.4 & 14.1 & 3.1 & {$[26,22]$} \\
\hline$n$-Hexane $+n$-octane & 25 & $\begin{array}{l}295.00- \\
23.00\end{array}$ & 0 & 0 & 0.3 & 0.9 & 0.4 & 0.5 & 0.6 & {$[25]$} \\
\hline$n$-Octane $+n$-tetradecane & 24 & 298.15 & 0 & 0 & 5 & 9.4 & 2.6 & 6.3 & 2 & [24] \\
\hline \multicolumn{11}{|l|}{ Nonpolar + nonpolar } \\
\hline $\begin{array}{l}\text { Carbon tetrachloride }+ \\
\text { cyclohexane }\end{array}$ & 16 & $\begin{array}{l}298.15- \\
308.15\end{array}$ & -38.6275 & 45.2095 & 0.2 & 0.2 & 0.2 & 0.2 & 0.2 & {$[27,22]$} \\
\hline $\begin{array}{l}n \text {-Hexane }+ \text { carbon } \\
\text { tetrachloride }\end{array}$ & 12 & $\begin{array}{l}298.15- \\
303.15\end{array}$ & -41.6152 & 43.1222 & 0.7 & 1.7 & 1 & 1 & 1 & [28] \\
\hline $\begin{array}{l}n \text {-Heptane }+ \text { carbon } \\
\text { tetrachloride }\end{array}$ & 6 & 303.15 & -32.6056 & 30.9176 & 0.7 & 1.5 & 0.9 & 0.7 & 1 & [28] \\
\hline
\end{tabular}




\begin{tabular}{|c|c|c|c|c|c|c|c|c|c|c|}
\hline $\begin{array}{l}n \text {-Octane }+ \text { carbon } \\
\text { tetrachloride }\end{array}$ & 6 & 303.15 & -39.302 & 36.8812 & 2.5 & 1.4 & 2.3 & 3.2 & 2.8 & [29] \\
\hline $\begin{array}{l}n \text {-Decane }+ \text { carbon } \\
\text { tetrachloride }\end{array}$ & 4 & 298.15 & 129.3732 & -100.1124 & 0.4 & 1.9 & 0.3 & 1.3 & 0.9 & {$[29,21]$} \\
\hline $\begin{array}{l}\text { Dodecane }+ \text { carbon } \\
\text { tetrachloride }\end{array}$ & 4 & 298.15 & 132.3892 & -100.5871 & 0.5 & 5.1 & 0.5 & 4.7 & 0.5 & [29] \\
\hline $\begin{array}{l}\text { 3-Methylpentane }+ \text { carbon } \\
\text { tetrachloride }\end{array}$ & 6 & 303.15 & -15.88 & 15.4745 & 0.7 & 2.7 & 1.2 & 1.3 & 1.2 & {$[30]$} \\
\hline $\begin{array}{l}\text { 2,3-Dimethylpentane }+ \\
\text { carbon tetrachloride }\end{array}$ & 6 & 303.15 & 64.6053 & -53.9069 & 0.3 & 3.1 & 0.3 & 1.3 & 0.3 & [29] \\
\hline 2,2,4-Trimethylpentane + & 6 & 303.15 & -26.7465 & 25.6102 & 0.4 & 2.5 & 1.6 & 1 & 1.8 & [29] \\
\hline Benzene $+n$-hexane & 11 & 298.15 & 145.7153 & -83.6627 & 0.4 & 3.5 & 0.3 & 2.1 & 0.5 & {$[31,32]$} \\
\hline Benzene $+n$-heptane & 34 & $\begin{array}{l}293.15- \\
358.15\end{array}$ & -63.0805 & 80.5367 & 4.8 & 3.8 & 4.5 & 3.7 & 4.1 & [32] \\
\hline Cyclohexane + benzene & 69 & $\begin{array}{l}293.15- \\
333.15\end{array}$ & 17.4422 & -3.747 & 1.2 & 2.1 & 1.2 & 2.1 & 0.9 & [33-36] \\
\hline \multicolumn{11}{|l|}{ Nonpolar + polar } \\
\hline$n$-Hexane + chloroform & 6 & 303.15 & 91.8544 & -62.6214 & 1.1 & 5 & 1.1 & 4 & 1.1 & {$[30]$} \\
\hline$n$-Heptane + chloroform & 6 & 303.15 & 141.5674 & -98.788 & 0.7 & 3.6 & 0.7 & 3.1 & 1.7 & {$[30]$} \\
\hline$n$-Octane + chloroform & 6 & 303.15 & 127.8976 & -90.0145 & 0.5 & 4.7 & 0.5 & 4.2 & 1.4 & [30] \\
\hline $\begin{array}{l}\text { Chloroform }+ \text { carbon } \\
\text { tetrachloride }\end{array}$ & 12 & 298.15 & -59.4366 & 82.5829 & 1.1 & 2.1 & 1.1 & 1.9 & 1.1 & {$[37]$} \\
\hline $\begin{array}{l}\text { 3-Methylpentane }+ \\
\text { chloroform }\end{array}$ & 6 & 303.15 & -27.7578 & 51.8701 & 0.7 & 5.7 & 0.7 & 4.5 & 0.6 & {$[30]$} \\
\hline $\begin{array}{l}\text { 2,3-Dimethylpentane }+ \\
\text { chloroform }\end{array}$ & 6 & 303.15 & 28.1744 & -17.9382 & 1.1 & 4.1 & 1.1 & 3.3 & 0.8 & [30] \\
\hline $\begin{array}{l}2,2,4 \text {-Trimethylpentane }+ \\
\text { chloroform }\end{array}$ & 6 & 303.15 & 29.0131 & -19.1057 & 0.4 & 5.8 & 0.4 & 5.2 & 0.8 & [30] \\
\hline
\end{tabular}


Table 2 (continued)

\begin{tabular}{|c|c|c|c|c|c|c|c|c|c|c|}
\hline \multirow{3}{*}{$\begin{array}{l}\text { System (component } \\
1+\text { component } 2 \text { ) }\end{array}$} & \multirow{3}{*}{$\begin{array}{l}\text { No. of } \\
\text { data } \\
\text { points }\end{array}$} & \multirow{3}{*}{$\begin{array}{l}\text { Temp. } \\
\text { range }(\mathrm{K})\end{array}$} & \multicolumn{2}{|c|}{ UNIDIF parameters (K) } & \multicolumn{5}{|c|}{$\operatorname{AAD}(\%)^{\mathrm{a}}$} & \multirow[t]{3}{*}{ References } \\
\hline & & & \multirow[t]{2}{*}{$\overline{a_{21}}$} & \multirow[t]{2}{*}{$a_{12}$} & \multicolumn{2}{|c|}{ Modified darken } & \multicolumn{2}{|l|}{ Vignes } & \multirow[t]{2}{*}{ UNIDIF } & \\
\hline & & & & & $\overline{\text { NRTL }}$ & $\overline{\text { UNIQUAC }}$ & $\overline{\text { NRTL }}$ & UNIQUAC & & \\
\hline \multicolumn{11}{|l|}{ Nonpolar + polar } \\
\hline Acetone + benzene & 31 & 298.15 & 91.7255 & -45.923 & 1.7 & 2.2 & 1.7 & 1.9 & 1.5 & {$[8,36,38]$} \\
\hline $\begin{array}{l}\text { Acetone }+ \text { carbon } \\
\text { tetrachloride }\end{array}$ & 12 & $\begin{array}{l}298.15- \\
298.30\end{array}$ & 221.6764 & -108.5594 & 4.4 & 6.5 & 4.2 & 6 & 4.8 & {$[39,38]$} \\
\hline Acetone + cumene & 12 & $\begin{array}{l}283.15- \\
303.15\end{array}$ & 138.6635 & -62.2699 & 1.7 & 8.8 & 1.7 & 8.6 & 3.4 & {$[40]$} \\
\hline Acetone + cyclohexane & 9 & 298.15 & 186.2569 & -37.7967 & 6.7 & 15.5 & 6.2 & 14.4 & 2.9 & [41] \\
\hline $\begin{array}{l}\text { Methyl ethyl ketone + } \\
\text { carbon tetrachloride }\end{array}$ & 7 & 298.15 & 168.5107 & -95.9914 & 1.9 & 3.5 & 1.8 & 2.6 & 0.8 & [42] \\
\hline $\begin{array}{l}\text { Acetic acid + carbon } \\
\text { tetrachloride }\end{array}$ & 9 & 298.15 & -9.7821 & 85.3011 & 1.6 & 7.4 & 1.6 & 7.4 & 1.7 & [8] \\
\hline Isobutyric acid + cumene & 12 & $\begin{array}{l}283.15- \\
303.15\end{array}$ & 102.9102 & -71.1125 & 1.5 & 2.4 & 1.5 & 2.3 & 1 & [39] \\
\hline Methanol + benzene & 8 & 313.15 & 434.508 & -22.1893 & 10.9 & 15.9 & 10.6 & 15.5 & 3 & [40] \\
\hline Ethanol + benzene & 17 & $\begin{array}{l}298.30- \\
313.13\end{array}$ & 280.2374 & -76.9792 & 14.4 & 7.8 & 14.2 & 7.9 & 3 & [39] \\
\hline $\begin{array}{l}\text { Methanol + carbon } \\
\text { tetrachloride }\end{array}$ & 11 & 293.15 & 545.7224 & -22.3977 & 39.4 & 49 & 39.4 & 49 & 8.8 & [43] \\
\hline $\begin{array}{l}\text { Ethanol + carbon } \\
\text { tetrachloride }\end{array}$ & 9 & 298.15 & 231.8918 & -76.4117 & 1.8 & 13 & 1.8 & 12.7 & 3.4 & {$[42]$} \\
\hline $\begin{array}{l}n \text {-Propanol + carbon } \\
\text { tetrachloride }\end{array}$ & 11 & 293.15 & 225.1052 & -104.6465 & 12.2 & 11.6 & 12.1 & 11.4 & 6.6 & {$[43]$} \\
\hline $\begin{array}{l}n \text {-Butanol + carbon } \\
\text { tetrachloride }\end{array}$ & 11 & 293.15 & 178.3019 & -100.6528 & 7.9 & 6.6 & 7.9 & 6.6 & 4.5 & {$[43]$} \\
\hline $\begin{array}{l}n \text {-Propanol + toluene } \\
\text { Polar }+ \text { polar }\end{array}$ & 15 & 298.15 & 217.6398 & -37.2243 & 25.4 & 26.2 & 23.2 & 22.3 & 9.3 & {$[44]$} \\
\hline Diethyl ether + chloroform & 8 & 298.15 & -10.7778 & -23.1012 & 1 & 3.4 & 1.2 & 4.5 & 0.8 & [45] \\
\hline Acetone + chloroform & 43 & $\begin{array}{l}298.15- \\
328.15\end{array}$ & 67.6603 & -78.6114 & 2.1 & 1.9 & 2.1 & 2.1 & 1.5 & {$[46,39,36,47]$} \\
\hline
\end{tabular}




\begin{tabular}{|c|c|c|c|c|c|c|c|c|c|c|}
\hline $\begin{array}{l}\text { Acetone }+ \\
\text { 1,2-dichlorobenzene }\end{array}$ & 13 & $\begin{array}{l}283.15- \\
303.15\end{array}$ & 35.5799 & 10.0297 & 2 & 8.6 & 2.2 & 6.1 & 1.8 & {$[40]$} \\
\hline Chloroform + acetic acid & 28 & 298.15 & 7.7763 & -18.7927 & 0.9 & 1.4 & 0.9 & 1.5 & 0.9 & [48] \\
\hline $\begin{array}{l}\text { Acetic acid }+ \\
\text { 5-methyl-2-hexanone }\end{array}$ & 19 & $\begin{array}{l}283.15- \\
303.15\end{array}$ & 56.6768 & -61.9336 & 2.3 & 3.1 & 2.3 & 3.1 & 3.5 & [40] \\
\hline $\begin{array}{l}\text { Acetic acid }+ \text { methyl } \\
\text { isobutyl ketone }\end{array}$ & 20 & $\begin{array}{l}283.15- \\
303.15\end{array}$ & 6.123 & -22.667 & 1.8 & 1.8 & 2 & 1.4 & 1.3 & {$[40]$} \\
\hline Acetic acid $+n$-butyl acetate & 18 & $\begin{array}{l}283.15- \\
303.15\end{array}$ & 58.9295 & -62.9653 & 1.2 & 3 & 1.5 & 2.4 & 2.2 & {$[40]$} \\
\hline Acetic acid + water & 19 & $\begin{array}{l}283.15- \\
303.15\end{array}$ & 148.1547 & -14.3877 & 7.2 & 6.4 & 7.1 & 6.1 & 4.7 & {$[40]$} \\
\hline Isobutyric acid + water & 14 & $\begin{array}{l}283.15- \\
303.15\end{array}$ & 270.1402 & 36.7759 & 39.3 & 56.1 & 39.3 & 56 & 6 & {$[40]$} \\
\hline Acetone + water & 45 & $\begin{array}{l}298.15- \\
328.15\end{array}$ & 152.4723 & 81.2199 & 17.4 & 17.1 & 13.8 & 13.5 & 3.5 & {$[39,36,47]$} \\
\hline $\begin{array}{l}\text { Methyl isopropyl } \\
\text { ketone }+ \text { water }\end{array}$ & 8 & $\begin{array}{l}293.15- \\
298.15\end{array}$ & 137.0036 & 130.5447 & 1.3 & 8.6 & 1.1 & 7.9 & 0.9 & [9] \\
\hline Methanol + water & 25 & $\begin{array}{l}278.15- \\
313.13\end{array}$ & 194.5302 & -10.7575 & 9 & 3.8 & 8.5 & 3.4 & 2.5 & {$[49,50]$} \\
\hline Ethanol + water & 24 & $\begin{array}{l}313.15- \\
346.15\end{array}$ & 215.7552 & -67.3855 & 14.1 & 9.6 & 14.1 & 9.6 & 5.2 & [47] \\
\hline$n$-Butanol + water & 36 & 298.15 & 217.281 & -68.992 & 11.1 & 11.9 & 10.8 & 11.2 & 2.8 & [9] \\
\hline $\begin{array}{l}\text { Dimethylformamide + } \\
\text { water }\end{array}$ & 10 & 278.15 & 61.7660 & -3.5889 & 2 & 26.9 & 1.7 & 10.4 & 1.4 & [13] \\
\hline $\begin{array}{l}n \text {-Methylpyrrolidone }+ \\
\text { water }\end{array}$ & 10 & 278.15 & 136.4422 & -54.0832 & 8.2 & 34.8 & 8.1 & 26.6 & 3.1 & [13] \\
\hline Grand average & 1042 & & & & 5.6 & 7.6 & 5.1 & 6.7 & 2.3 & \\
\hline
\end{tabular}

${ }^{\mathrm{a}} \mathrm{AAD}(\%)=\sum_{i=1}^{n}\left|\left(D_{12, i}^{\mathrm{cal}}-D_{12, i}^{\text {exp }}\right) /\left(D_{12, i}^{\text {exp }}\right)\right| \times 100$. 
positions $\left(\lambda^{2}\right)$. For a fluid mixture, a thermodynamic factor, which is the partial derivative of activity with respect to composition, can be combined with the averaged limiting diffusion coefficients to express the mutual diffusion coefficient. On the other hand, the diffusion coefficient can be written in as the product of $\lambda_{m}^{2}$ and $k_{a m}$ from the absolute reaction rate theory. Taking the $k_{a m}$ in Eq. (7) as an effective specific rate where the nonideality of the fluid mixture is included in the local composition parameters, the diffusion coefficient is then written as:

$$
D=\lambda_{m}^{2} k_{a m}=\lambda_{m}^{2} \prod_{i=1}^{n}\left(\frac{k T}{2 \pi m_{i}}\right)^{x_{i} / 2} \exp \left(\frac{z}{2 k T} \sum_{i=1}^{n} x_{i} q_{i} \sum_{j=1}^{n} U_{j i} \theta_{j i}\right)
$$

where the distance parameter is assumed to follow the simple mixing rule

$$
\lambda_{m}=\sum x_{i} \lambda_{i}
$$

To derive the mutual diffusion coefficient, we consider a lattice fluid mixture consisting of components 1 and 2. When these two components interchange their positions, there results changes in the frequency of movement and the distance of equilibrium position. Since $k_{a m}$ and $\lambda_{m}$ are functions of composition, their derivatives with respect to the composition of component $i$ ( $i=1$ or 2$)$ are

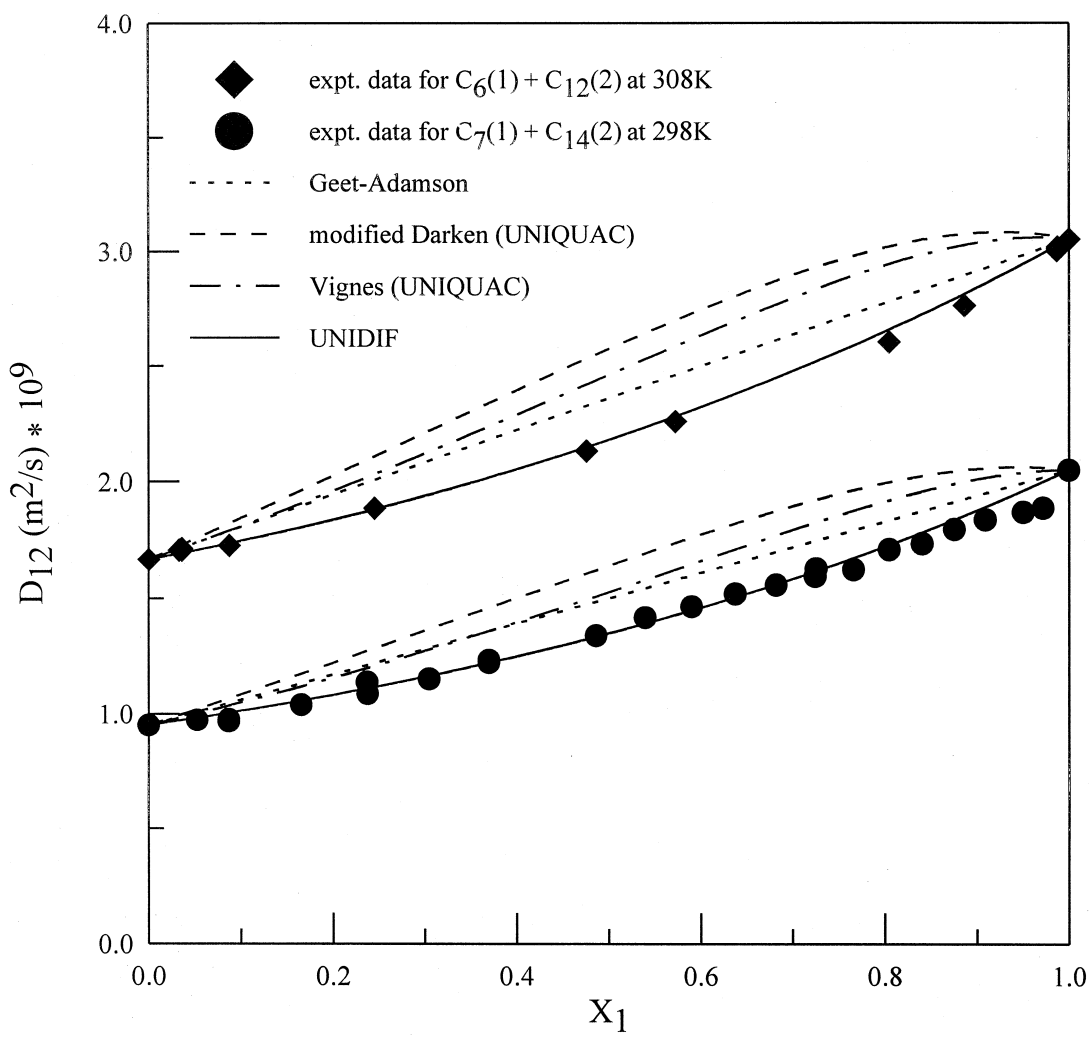

Fig. 1. Calculation results for the mutual diffusion coefficients of the binary mixtures of $n$-alkenes. 


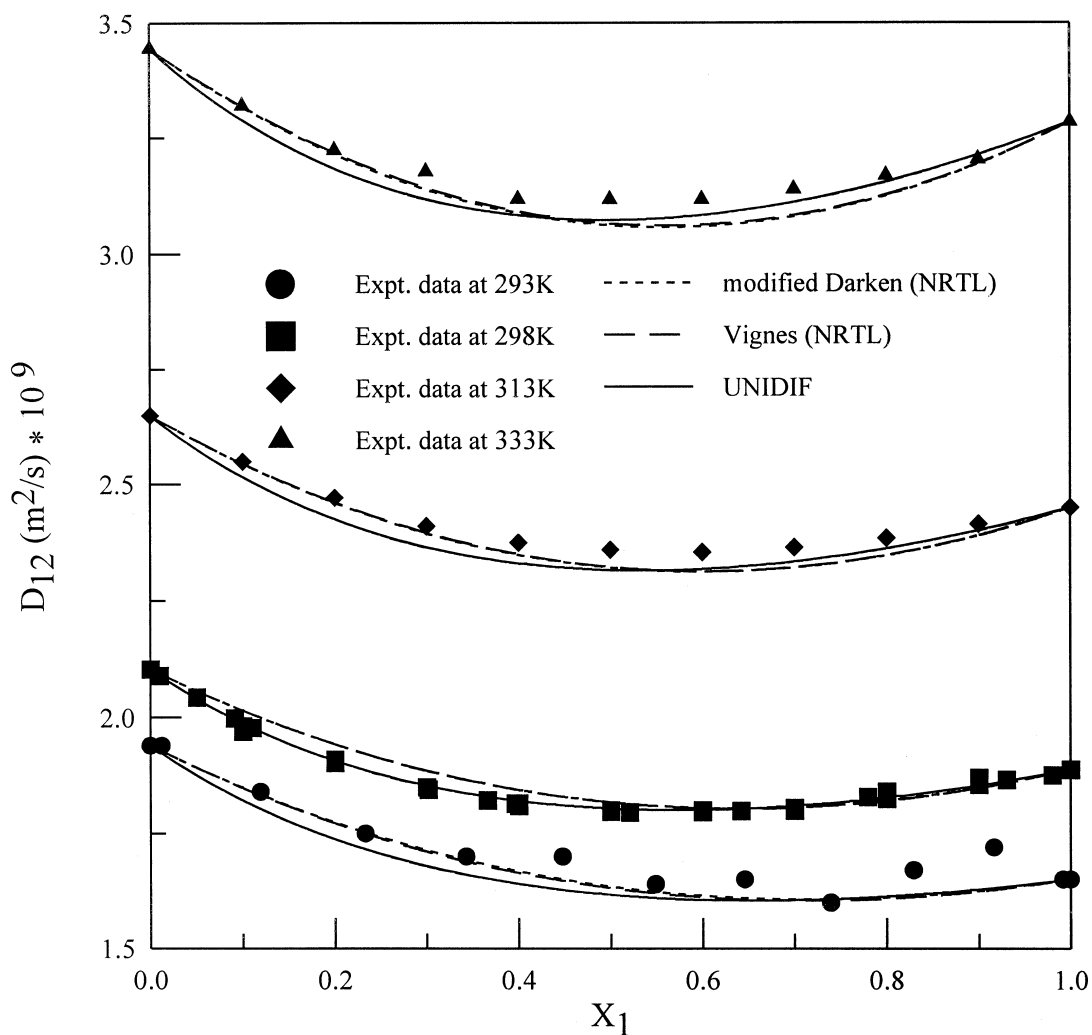

Fig. 2. Calculation results for the mutual diffusion coefficients of the binary mixture cyclohexane(1) + benzene(2) at various temperatures.

required to express the effect due to the interchange of molecular positions in the mutual diffusion process. Also, the number of available sites for the movement of component $i$ ( $i=1$ or 2$)$ during the mutual diffusion process is proportional to the mole fraction of the other component. The product of the number of available sites for the molecular movement and the derivatives of the frequency or distance parameter with respect to composition gives the effective absolute reaction rate parameters for the mutual diffusion process:

$$
\begin{aligned}
& \ln k_{a, 12}=x_{2}\left[\frac{\partial\left(n \ln k_{a m}\right)}{\partial n_{1}}\right]_{T, P, n_{2}}+x_{1}\left[\frac{\partial\left(n \ln k_{a m}\right)}{\partial n_{2}}\right]_{T, P, n_{1}} \\
& \ln \lambda_{12}=x_{2}\left[\frac{\partial\left(n \ln \lambda_{m}\right)}{\partial n_{1}}\right]_{T, P, n_{2}}+x_{1}\left[\frac{\partial\left(n \ln \lambda_{m}\right)}{\partial n_{2}}\right]_{T, P, n_{1}}
\end{aligned}
$$

where $k_{a m}$ and $\lambda_{m}$ are expressed by Eqs. (7) and (9) for a binary mixture, respectively. The mutual diffusion coefficient for a binary mixture is then written analogously to Eq. (8) as

$$
\ln D_{12}=2 \ln \lambda_{12}+\ln k_{a, 12}
$$




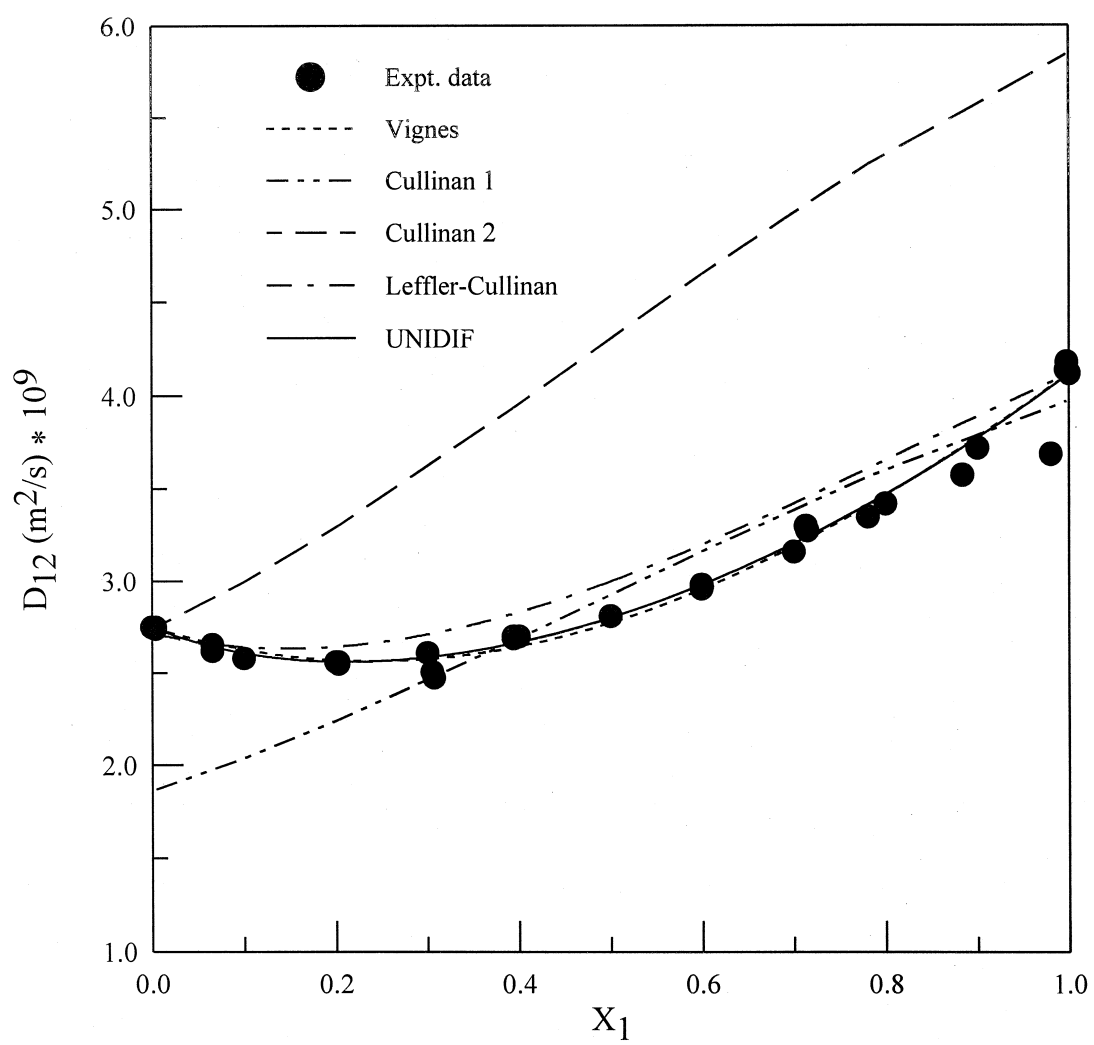

Fig. 3. Comparison of the calculated results for the mutual diffusion coefficients of the binary mixture acetone(1)+benzene(2) at $298 \mathrm{~K}$ from various correlation methods.

Substituting the expressions of $k_{a, 12}$ and $\lambda_{12}$, the mutual diffusion coefficient is:

$$
\begin{aligned}
\ln D_{12}= & \ln D_{21} \\
= & 2\left\{\ln \left(x_{1} \lambda_{1}+x_{2} \lambda_{2}\right)+\frac{x_{2} \lambda_{1}+x_{1} \lambda_{2}}{x_{1} \lambda_{1}+x_{2} \lambda_{2}}-1\right\} \\
& +\frac{1}{2}\left\{x_{2} \ln \frac{k T}{2 \pi m_{1}}+x_{1} \ln \frac{k T}{2 \pi m_{2}}\right\}+\frac{z}{2 k T}\left\{x_{2} q_{1} U_{11}+x_{1} q_{2} U_{22}\right\} \\
& -\left\{x_{2} q_{1}\left(\theta_{21}^{2} \ln \tau_{21}+\theta_{22}^{2} \tau_{12} \ln \tau_{12}\right)+x_{1} q_{2}\left(\theta_{12}^{2} \ln \tau_{12}+\theta_{11}^{2} \ln \tau_{21}\right)\right\}
\end{aligned}
$$

The mutual diffusion coefficient in Eq. (13) is divided into two parts, representing the combinatorial and residual contributions, respectively:

$$
\ln D_{12}=\ln D_{12}^{\text {combinatorial }}+\ln D_{12}^{\text {residual }}
$$




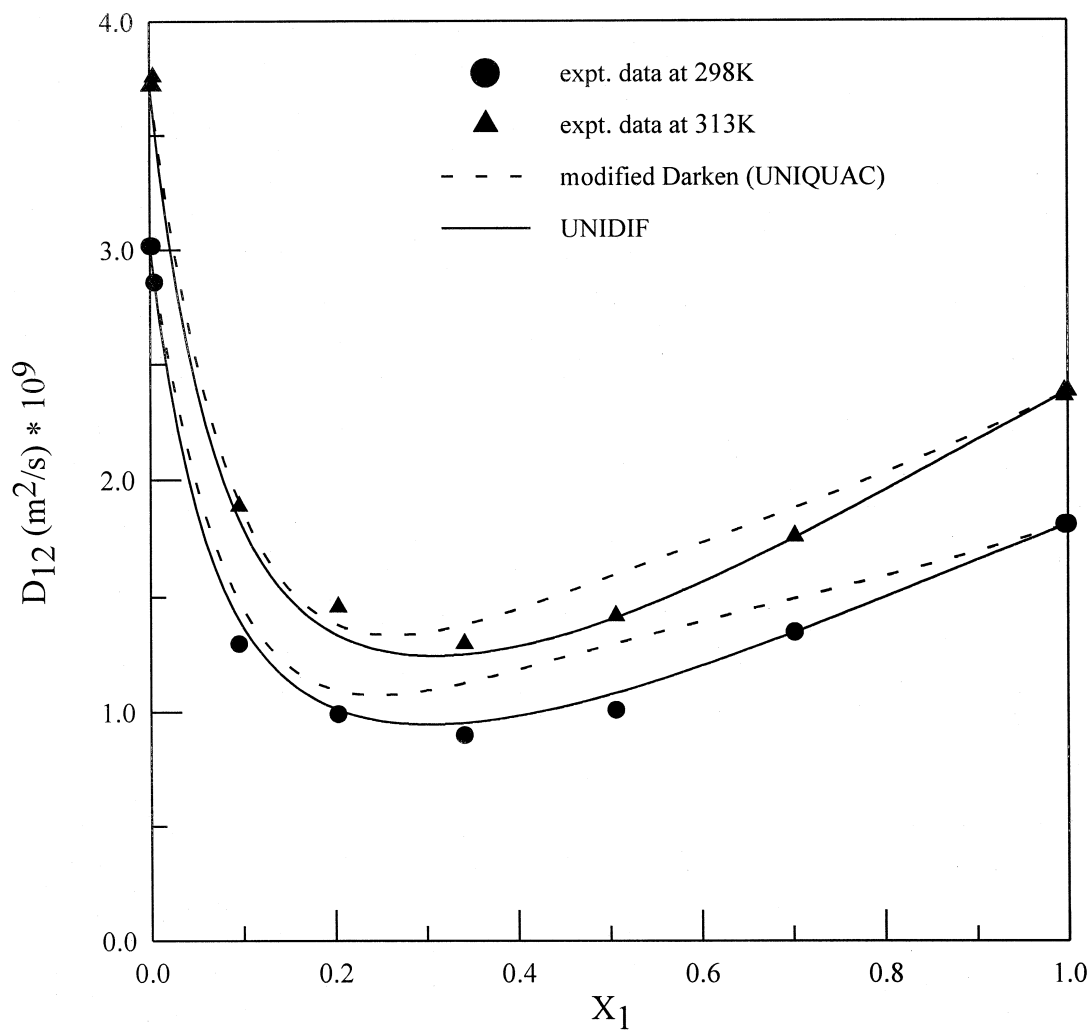

Fig. 4. Calculation results for the mutual diffusion coefficients of the binary mixture ethanol(1) + benzene(2) at various temperatures.

where

$$
\begin{aligned}
\ln D_{12}^{\text {combinatorial }}= & 2\left\{\ln \left(x_{1} \lambda_{1}+x_{2} \lambda_{2}\right)+\frac{x_{2} \lambda_{1}+x_{1} \lambda_{2}}{x_{1} \lambda_{1}+x_{2} \lambda_{2}}-1\right\} \\
& +\frac{1}{2}\left\{x_{2} \ln \frac{k T}{2 \pi m_{1}}+x_{1} \ln \frac{k T}{2 \pi m_{2}}\right\}+\frac{z}{2 k T}\left\{x_{2} q_{1} U_{11}+x_{1} q_{2} U_{22}\right\}
\end{aligned}
$$

and

$$
-\ln D_{12}^{\text {residual }}=x_{2} q_{1}\left(\theta_{21}^{2} \ln \tau_{21}+\theta_{22}^{2} \tau_{12} \ln \tau_{12}\right)+x_{1} q_{2}\left(\theta_{12}^{2} \ln \tau_{12}+\theta_{11}^{2} \tau_{21} \ln \tau_{21}\right)
$$

At the limiting condition of infinite dilution, the diffusion coefficients for both components in a binary liquid mixture are obtained from Eq. (13) at $x_{1}=0$ and $x_{2}=0$ :

$$
\ln D_{1}^{0}=2\left\{\ln \lambda_{2}+\frac{\lambda_{1}}{\lambda_{2}}-1\right\}+\frac{1}{2} \ln \frac{k T}{2 \pi m_{1}}+\frac{z q_{1} U_{11}}{2 k T}-q_{1}\left(\ln \tau_{21}+\tau_{12} \ln \tau_{12}\right)
$$

and

$$
\ln D_{2}^{0}=2\left\{\ln \lambda_{1}+\frac{\lambda_{2}}{\lambda_{1}}-1\right\}+\frac{1}{2} \ln \frac{k T}{2 \pi m_{2}}+\frac{z q_{2} U_{22}}{2 k T}-q_{2}\left(\ln \tau_{12}+\tau_{21} \ln \tau_{21}\right)
$$


Based on these expressions, the mutual diffusion coefficient of a binary mixture can be expressed in terms of the limiting values and the following composition dependence:

$$
\begin{aligned}
\ln D_{12}= & x_{2} \ln D_{1}^{0}+x_{1} \ln D_{2}^{0} \\
& +2\left\{x_{1} \ln \frac{x_{1}}{\phi_{1}}+x_{2} \ln \frac{x_{2}}{\phi_{2}}\right\}+2 x_{1} x_{2}\left\{\frac{\phi_{1}}{x_{1}}\left(1-\frac{\lambda_{1}}{\lambda_{2}}\right)+\frac{\phi_{2}}{x_{2}}\left(1-\frac{\lambda_{2}}{\lambda_{1}}\right)\right\} \\
& +\left\{x_{2} q_{1}\left[\left(1-\theta_{21}^{2}\right) \ln \tau_{21}+\left(1-\theta_{22}^{2}\right) \tau_{12} \ln \tau_{12}\right]\right. \\
& \left.+x_{1} q_{2}\left[\left(1-\theta_{12}^{2}\right) \ln \tau_{12}+\left(1-\theta_{11}^{2}\right) \tau_{21} \ln \tau_{21}\right]\right\}
\end{aligned}
$$

where $\phi_{i}(i=1$ or 2$)$ is defined as

$$
\phi_{i}=\frac{x_{i} \lambda_{i}}{\sum_{i=1}^{2} x_{i} \lambda_{i}}
$$

Eq. (19) is employed in correlating the mutual diffusion coefficients of binary liquid mixtures. It is named the UNIDIF equation since it resembles the functional expression of the UNIQUAC model. To

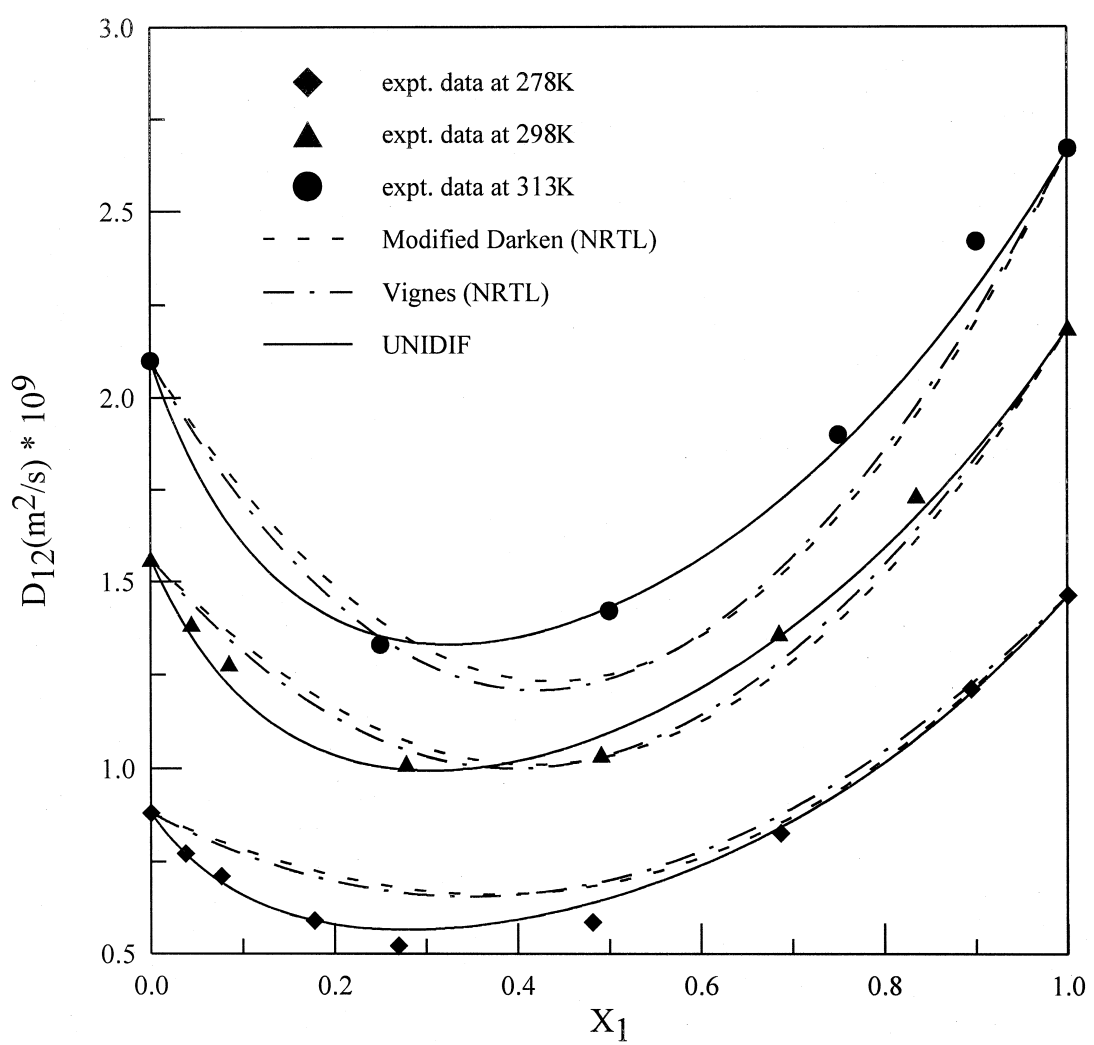

Fig. 5. Comparison of the calculated results for the mutual diffusion coefficients of the binary mixture methanol(1) + water(2) from various correlation methods. 
apply the UNIDIF equation, the limiting diffusion coefficients are taken from either experimental data or from empirical correlation equations. The equilibrium distance parameter $\lambda_{i}$ is assumed to be proportional to the cubic root of either the molecular volume or volume parameter $r_{i}$ in the UNIQUAC model. The interaction parameters $a_{i j}(i$ or $j=1$ or 2$)$ are regressed from experimental data of binary mutual diffusion coefficients.

\section{Results and discussion}

Mutual diffusion coefficients of binary nonpolar and polar liquid mixtures are correlated in this study using the UNIDIF model with two binary parameters. Calculation results from other correlation equations, as listed in Table 1, are also compared in this work. The correlative equations listed in Table 1 contain the limiting diffusion coefficients, molar volumes and viscosities of pure fluids, and the thermodynamic factor which is the partial derivative of the activity with respect to composition. The limiting diffusion coefficients are taken from experimental data whenever they are available. The thermodynamic factor required to compare the correlative equations listed in Table 1 is evaluated by employing either the UNIQUAC or the NRTL activity coefficient model, with the binary parameters

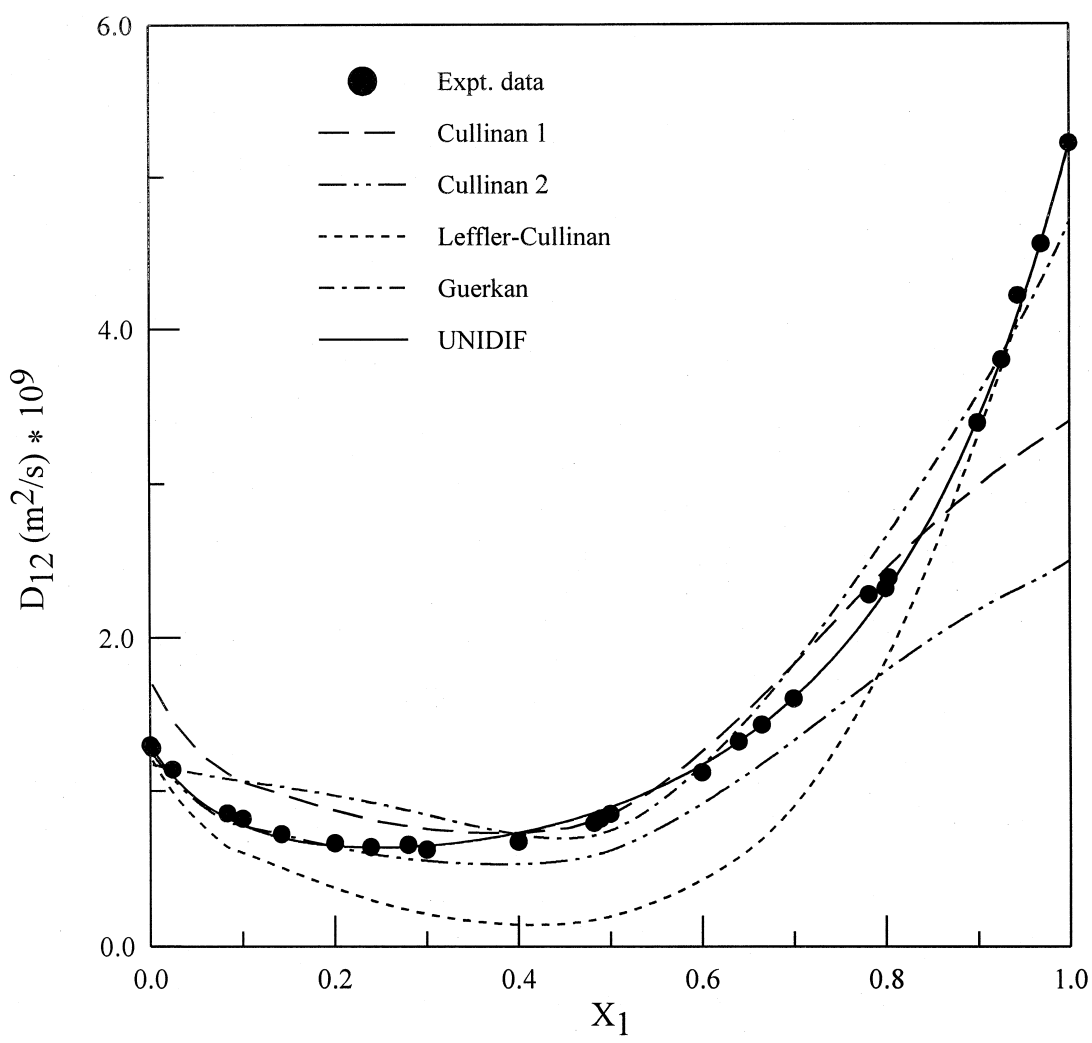

Fig. 6. Comparison of the calculated results for the mutual diffusion coefficients of the binary mixture acetone(1) + water(2) at $298 \mathrm{~K}$ from various correlation methods. 
in the activity coefficient models regressed using experimental mutual diffusion coefficient data. The calculation results of this study, and the comparison with those from the modified Darken and Vignes equations are listed in Table 2 . For the binary mixtures of $n$-alkanes, no binary interaction parameter in either model is included, and only the combinatorial part of the UNIQUAC equation is included in evaluating the thermodynamic factor for the modified Darken or Vignes equation. The calculation results from the UNIDIF model are satisfactory and the absolute average deviation (AAD) in mutual diffusion coefficient is $1.6 \%$, which is superior to those from the modified Darken or Vignes equations. Fig. 1 presents the comparison of the calculated results from the UNIDIF model for the $n$-alkane binary systems of $n$-hexane $+n$-dodecane and $n$-heptane $+n$-tetradecane with those from the modified Darken and the Vignes equations. It is demonstrated that the UNIDIF model gives good prediction results without any fitted parameter. The modified Darken and Vignes equations with thermodynamic factor evaluated from the combinatorial UNIQUAC model yield significant errors. For the nonpolar + nonpolar binary mixtures, the UNIDIF model yields comparable results to those from the other two correlative equations, all with their optimally fitted binary parameters, as shown in Table 2. Fig. 2 shows the calculated results of the mutual diffusion coefficients of cyclohexane + benzene at various temperatures. Three models give comparable results with their optimally fitted binary parameters. Fig. 3 shows a typical example for a polar + nonpolar binary mixture of acetone and benzene. Five models are compared for this binary mixture. The UNIDIF and the Vignes models

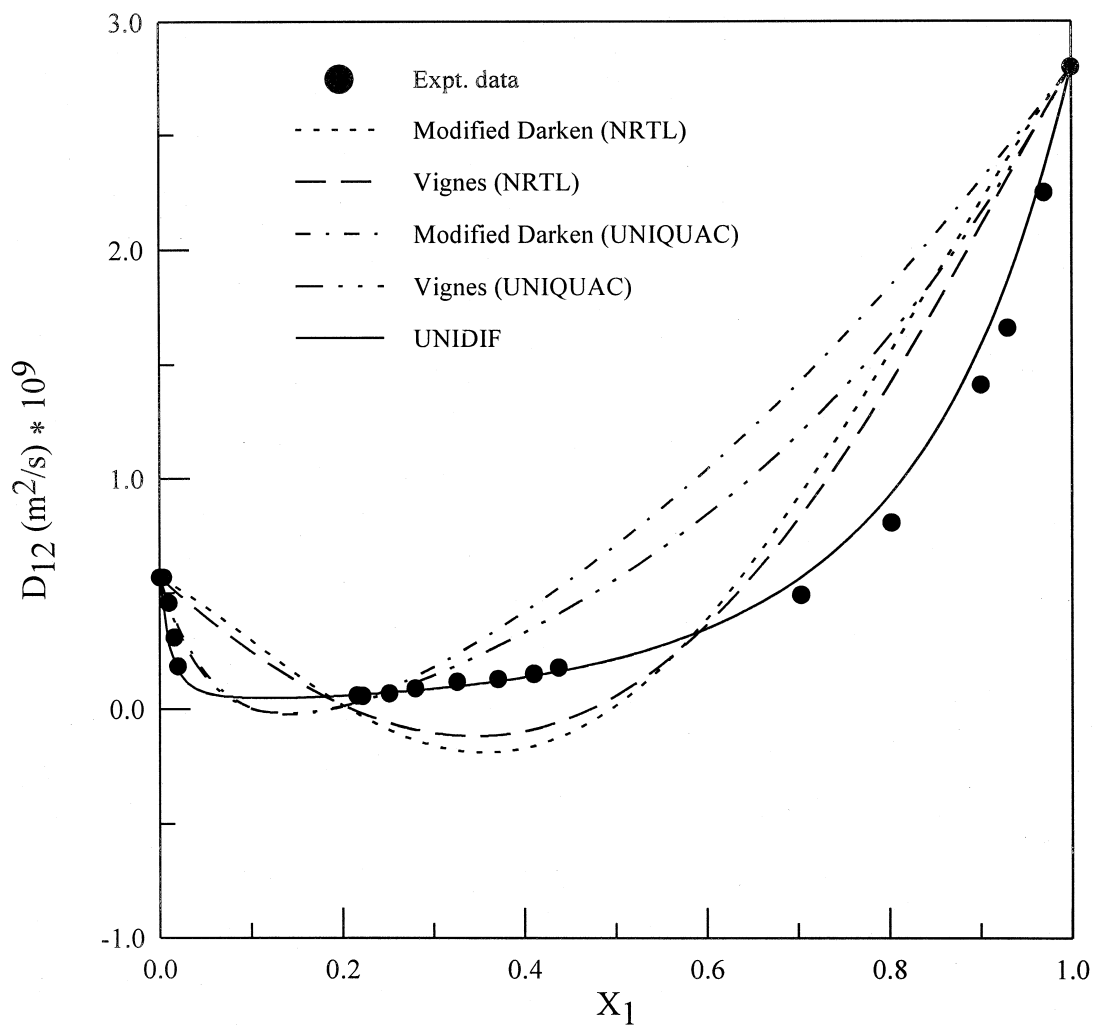

Fig. 7. Comparison of the calculated results for the mutual diffusion coefficients of the binary mixture triethylamine(1) + water(2) at $292 \mathrm{~K}$. 
used two best-fitted parameters for the diffusion coefficients, respectively. The results for the three Cullinan type equations are directly taken from the literature data [8] where the thermodynamic factors are evaluated based on the vapor-liquid equilibrium data. It is observed that the UNIDIF and the Vignes models give good calculation results while those predicted from Cullinan type equations show appreciable errors. Fig. 4 compares the calculated results for the polar + nonpolar mixture of ethanol and benzene. The UNIDIF model yields better agreement with experimental data than that from the modified Darken equation. Figs. 5 and 6 present the calculation results for the polar aqueous mixtures. In the methanol and water binary mixture shown in Fig. 5, satisfactory results are obtained from the UNIDIF model. The modified Darken and the Vignes equations, with thermodynamic factors fitted from the NRTL model, give larger errors. The calculated mutual diffusion coefficients for the acetone + water binary mixture from various models are shown in Fig. 6. Those predicted from the Cullinan type equations and the Guerkan equation are taken from literature [8] where the thermodynamic factors are evaluated based on the vapor-liquid equilibrium data. It is again demonstrated that the UNIDIF model gives good agreement with the experimental data. The other four models show appreciable deviations in the entire composition range. Fig. 7 shows the calculated mutual diffusion coefficient results for a partially miscible mixture of trimethylamine and water at $292.15 \mathrm{~K}$, where two-phase region exists between the mole fraction of trimethylamine of 0.0245 and 0.21 . With two temperature-independent binary parameters in the UNIDIF model, satisfactory agreement with the

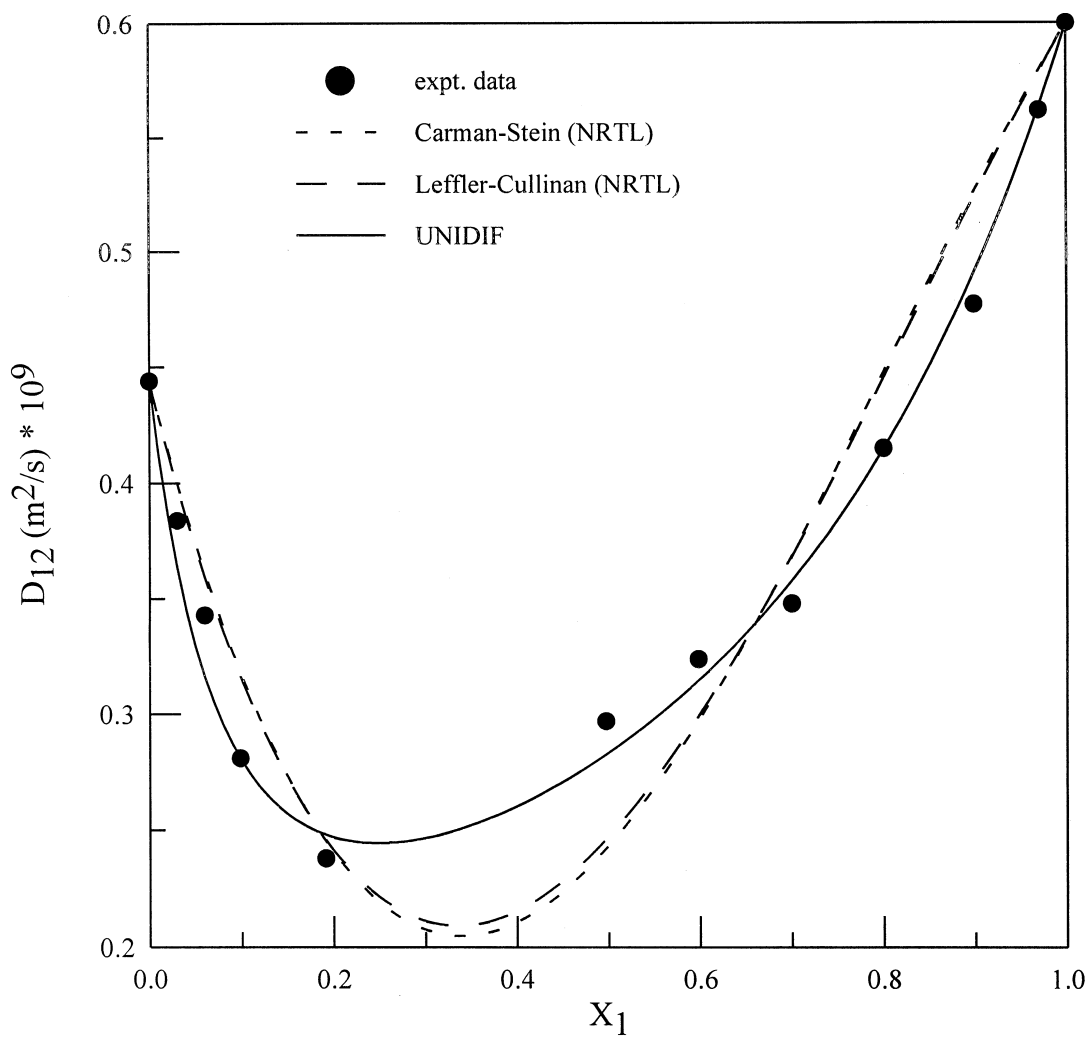

Fig. 8. Comparison of the calculated results for the mutual diffusion coefficients of the binary mixture $n$ methylpyrrolidone(1) + water(2) at $278 \mathrm{~K}$. 
Table 3

Correlations of the limiting diffusion coefficients of binary mixtures

\begin{tabular}{lll}
\hline Equations & Equation names & References \\
\hline$D_{\mathrm{AB}}^{0}=9.89 \times 10^{-8} T \eta_{\mathrm{B}}^{-0.907} V_{\mathrm{A}}^{-0.45} V_{\mathrm{B}}^{-0.265}$ & Siddiqi-Lucas & [5] \\
$D_{\mathrm{AB}}^{0}=\left(7.4 \times 10^{-8}\left(\phi M_{\mathrm{B}}\right)^{1 / 2} T\right) /\left(\eta_{\mathrm{B}} V_{\mathrm{A}}^{0.6}\right) ; \phi=$ association factor of solvent B & Wilke-Chang & [51] \\
$D_{\mathrm{AB}}^{0}=8.93 \times 10^{-8}\left(\left(V_{\mathrm{A}}\right) /\left(V_{\mathrm{B}}^{2}\right)\right)^{1 / 6}\left(\left(P_{\mathrm{B}}\right) /\left(P_{\mathrm{A}}\right)\right)^{0.6}(T) /\left(\eta_{\mathrm{B}}\right)$ & Tyn-Calus & {$[52]$} \\
$D_{\mathrm{AB}}^{0}=\left[\left(9.97 \times 10^{-8}\right) /\left(\left(I_{\mathrm{A}} V_{\mathrm{A}}\right)^{1 / 3}\right)+\left(2.40 \times 10^{-8} A_{\mathrm{B}} S_{\mathrm{B}} V_{\mathrm{B}}\right) /\left(I_{\mathrm{A}} S_{\mathrm{A}} V_{\mathrm{A}}\right)\right](T) /\left(\eta_{\mathrm{B}}\right) ;$ & Nakanishi & [53] \\
$I, S, A=$ adjustable parameters & & \\
\hline
\end{tabular}

experimental data is obtained for both coexisting liquid phases. The modified Darken and the Vignes equations, with thermodynamic factors fitted from either the UNIQUAC or the NRTL model, show large errors and even negative diffusion coefficients in some concentration ranges. Fig. 8 presents the calculated mutual diffusion coefficients for the binary mixture of $n$-methylpyrrolidone + water. The UNIDIF model yields satisfactory results with an AAD about 3\%. The other two models of Carman-Stein and Leffler-Cullinan contain viscosity and thermodynamic factor in their equations. The experimental data of viscosity are taken from literature $[13,14]$ and the thermodynamic factors are evaluated by fitting the mutual diffusion coefficient data from the NRTL equation. It is observed that

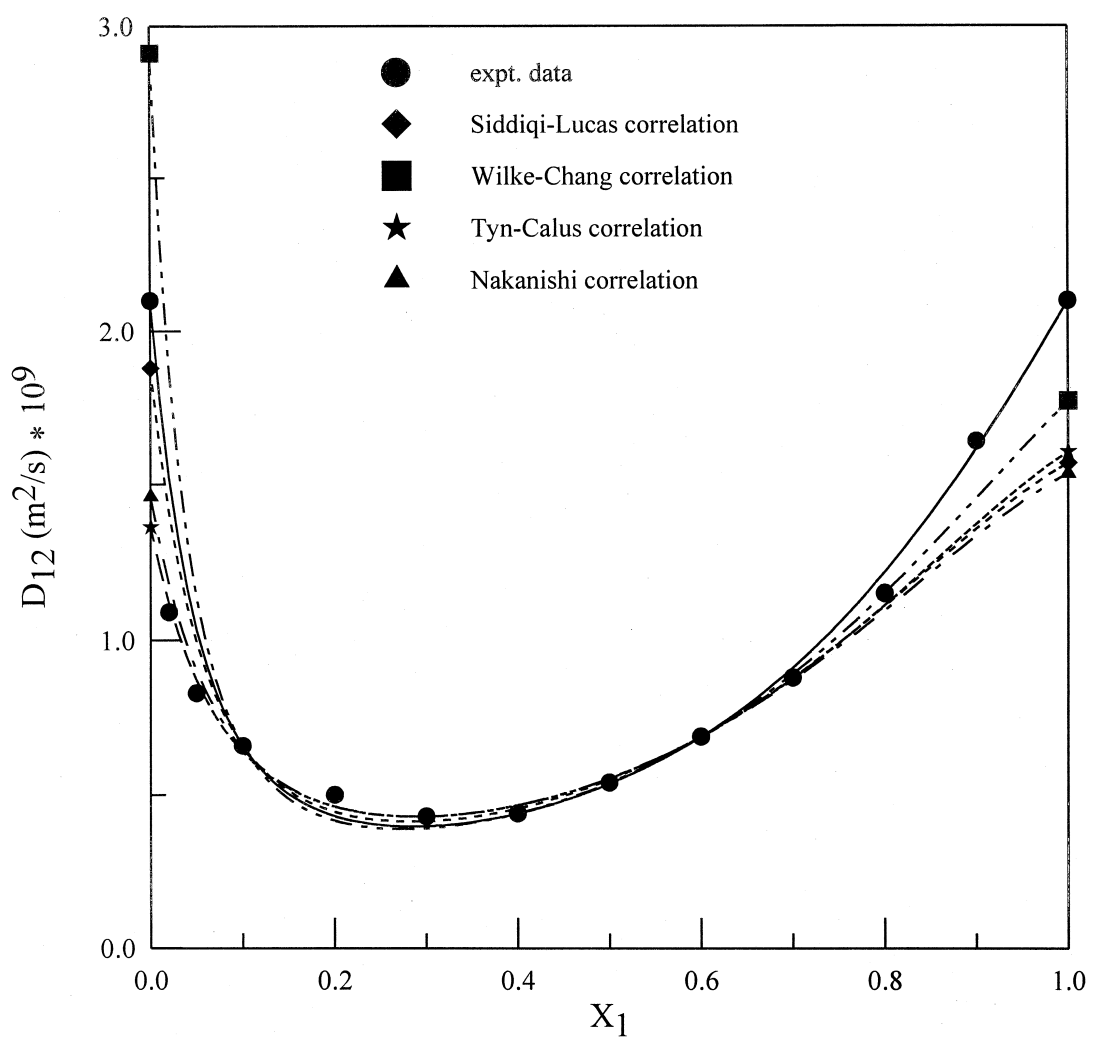

Fig. 9. Effect of the limiting diffusion coefficients on the correlation results for the binary mixture methanol(1) + carbon tetrachloride(2) at $293 \mathrm{~K}$. 
application of the viscosity effect does not bring useful contribution to the correlation of the mutual diffusion coefficients. Table 2 lists the comparison for the calculations of the mutual diffusion coefficients of polar + polar binary mixtures from various models. It is clearly observed that the UNIDIF model gives the best correlation results for the polar mixtures with an ADD about $3 \%$. The other models show relatively larger peak and average deviations for the polar systems, especially for the aqueous mixtures. This work used the experimental limiting diffusion coefficients as the reference points. Correlation equations for the limiting diffusion coefficients can be applied when no experimental data are available. Four empirical equations for the limiting diffusion coefficients are listed in Table 3. Fig. 9 shows a comparison of the calculation results for the binary mixture of methanol and carbon tetrachloride with various choices of the correlative equations of the limiting diffusion coefficients. It is demonstrated that the limiting diffusion coefficients have appreciable effect in correlating the mutual diffusion coefficients in the complete concentration range, and improved correlation equations for the limiting values are required in further studies. Fig. 10 shows a distribution of calculation errors for various binary mixtures using the UNIDIF model. The symbols in Fig. 10 represent various nonpolar and polar mixtures investigated in this study. We have correlated the mutual diffusion coefficients over 1000 data points at various temperatures. The UNIDIF model derived in this study with two temperature-independent binary parameters yields an overall AAD of $2.3 \%$, which is better than the results calculated from other models, as shown in Table 2. Fig. 10 shows that the difference between the experimental and the calculated mutual diffusion coefficients

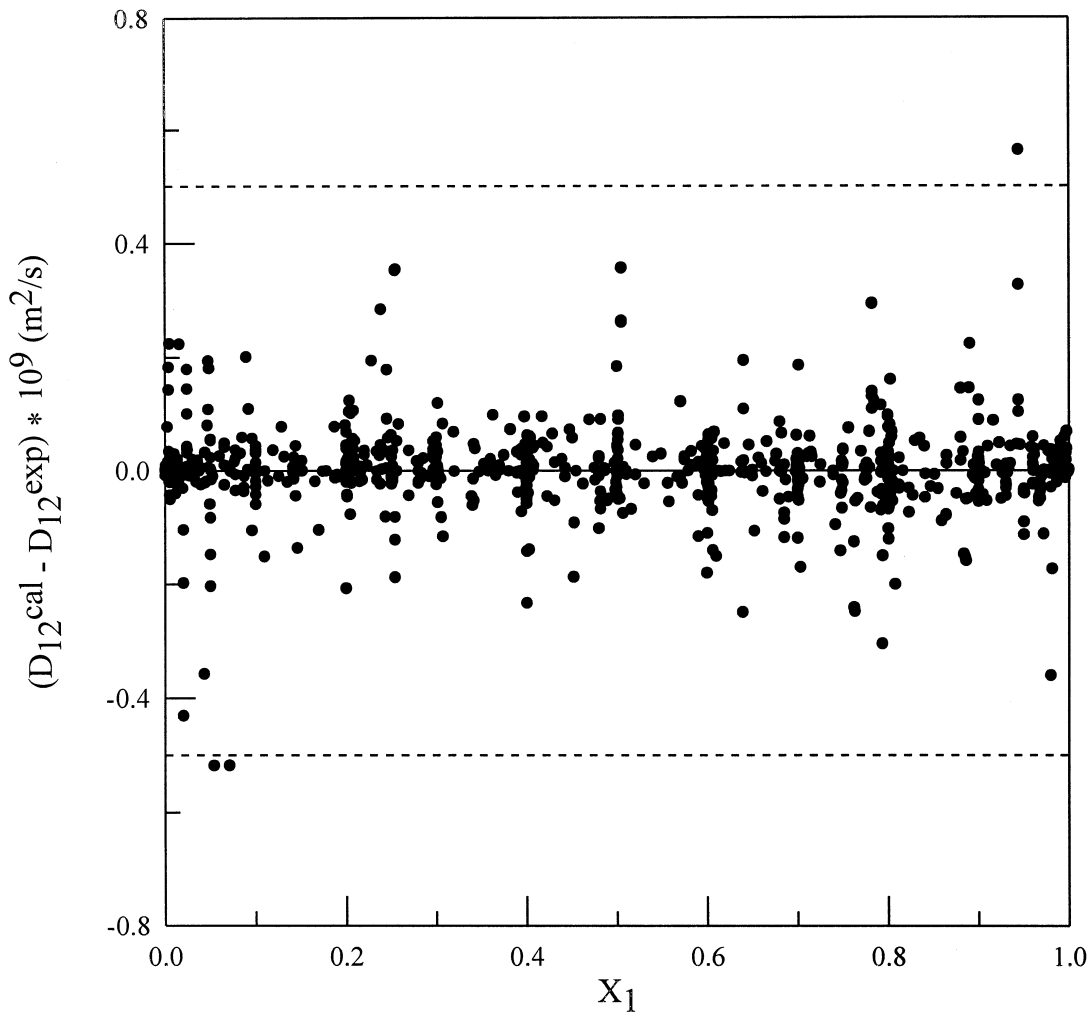

Fig. 10. Distributions of calculated errors from this study. 
from the UNIDIF model is within $\pm 0.5 \times 10^{-9} \mathrm{~m}^{2} / \mathrm{s}$. Further generalization to a group contribution model is currently undergoing.

\section{Conclusion}

A new correlative UNIDIF model for the mutual diffusion coefficients of binary liquid mixtures is developed in this study. This equation resembles the functional form of a UNIQUAC equation and two temperature-independent binary interaction parameters are included in the UNIDIF model. The best-fitted binary parameters of the UNIDIF model for extensive nonpolar and polar mixtures are investigated. Satisfactory correlation results are presented for the UNIDIF model of both the miscible and partially miscible systems. The UNIDIF model shows superior results to those from other correlative models with their optimal binary parameters.

\section{Notations}

$\begin{array}{ll}a & \text { Interaction energy } \\ D & \text { Diffusion coefficient } \\ h & \text { Planck constant } \\ k & \text { Boltzmann constant } \\ k_{a} & \text { The frequency of movement } \\ m & \text { Weight of a molecule } \\ n & \text { The number of components in a mixture } \\ N & \text { The number of molecules } \\ q & \text { Surface area fraction } \\ P & \text { Pressure } \\ T & \text { Temperature } \\ U & \text { Potential energy } \\ x & \text { Mole fraction } \\ z & \text { Coordination number }\end{array}$

Greek letters

$\begin{array}{ll}\lambda & \text { Diffusion length } \\ \tau & \text { Interaction parameter } \\ \theta & \text { Local composition parameter } \\ \phi & \text { The fraction of diffusion length, } \lambda \\ \omega & \text { The number of configurations of a lattice } \\ \Omega & \text { The partition function of a liquid mixture }\end{array}$

Superscripts

0

Infinite dilution

Subscripts

$i, j$

The property of component $i, j$

$m$

Mixture property 


\section{Acknowledgements}

The authors are grateful to the National Science Council, Republic of China for supporting this research.

\section{References}

[1] W. Cao, A. Fredenslund, P. Rasmussen, Statistical thermodynamic model for viscosity of pure liquids and liquid mixtures, Ind. Eng. Chem. Res. 31 (1992) 2603-2619.

[2] R.L. Rowley, A local composition model for multicomponent liquid mixture thermal conductivities, Chem. Eng. Sci. 37 (1982) 897-904.

[3] R.K. Ghai, H. Ertl, F.A.L. Dullien, Liquid diffusion of nonelectrolytes: Part 1, AIChE J. 19 (1973) 881-900.

[4] M.R. Riazi, C.H. Whitson, Estimating diffusion coefficients of dense fluids, Ind. Eng. Chem. Res. 32 (1993) 3081-3088.

[5] M.A. Siddiqi, K. Lucas, Correlations for prediction of diffusion in liquids, Can. J. Chem. Eng. 64 (1986) 839-843.

[6] E.L. Cussler, Cluster diffusion in liquids, AIChE J. 26 (1980) 43-51.

[7] H.T. Cullinan Jr., An explicit formulation of the theory of cluster diffusion, AIChE J. 31 (1985) 1740-1741.

[8] D.K. Rollins, K.S. Knaebel, Applicability of Cullinan's equation for liquid binary diffusivities, AIChE J. 37 (1991) 470-474.

[9] M. Pertler, E. Blass, G.W. Stevens, Fickian diffusion in binary mixtures that form two liquid phases, AIChE J. 42 (1996) 910-920.

[10] S. Glasstone, K.J. Laidler, H. Eyring, The Theory of Rate Processes, McGraw-Hill, New York (1941).

[11] E.A. Guggenheim, Mixtures, Clarendon Press, Oxford (1952).

[12] D.S. Abrams, J.M. Prausnitz, Statistical thermodynamics of liquid mixtures: a new expression for the excess Gibbs energy of partly or completely miscible systems, AIChE J. 21 (1975) 116-128.

[13] G. Guarino, O. Ortona, R. Sartorio, V. Vitagliano, Diffusion, viscosity, and refractivity data on the systems dimethylformamide-water and $n$-methylpyrrolidone-water at $5^{\circ} \mathrm{C}$, J. Chem. Eng. Data 30 (1985) $366-368$.

[14] V. Vitagliano, R. Sartorio, E. Chiaravalle, O. Ortona, Diffusion and viscosity in water-triethylamine mixtures at 19 and $20^{\circ} \mathrm{C}$, J. Chem. Eng. Data 25 (1980) 121-124.

[15] A.L.V. Geet, A.W. Adamson, Diffusion in liquid hydrocarbon mixtures, J. Phys. Chem. 68 (1964) $238-246$.

[16] R.C. Reid, J.M. Prausnitz, B.E. Poling, The Properties of Gases and Liquids, 4th edn., McGraw-Hill (1988).

[17] A. Vignes, Diffusion in binary solutions, Ind. Eng. Chem. Fundam. 5 (1966) 189-199.

[18] P.C. Carman, L.H. Stein, Self-diffusion in mixtures: 1, Trans. Farad. Soc. 52 (1956) 619-627.

[19] J. Leffler, H.T. Cullinan Jr., Variation of liquid diffusion coefficients with composition, Ind. Eng. Chem. Fundam. 9 (1970) 84-88.

[20] T. Guerkan, Note to the editor, AIChE J. 33 (1987) 175-176.

[21] D.L. Bidlack, D.K. Anderson, Mutual diffusion in nonideal, nonassociating liquid systems, J. Phys. Chem. 68 (1964) 3790-3794.

[22] W. Hayduk, S. Ioakimidis, Liquid diffusivities in normal paraffin solutions, J. Chem. Eng. Data 21 (1976) 255-260.

[23] J.C. Shieh, P.A. Lyons, Transport properties of liquid n-alkanes, J. Phys. Chem. 73 (1969) 3258-3264.

[24] H.Y. Lo, Diffusion coefficients in binary liquid n-alkane systems, J. Chem. Eng. Data 19 (1974) $236-241$.

[25] A.A. Alizadeh, W.A. Wakeham, Mutual diffusion coefficients for binary mixtures of normal alkanes, Int. J. Thermophys. 3 (1982) 307-323.

[26] D.L. Bidlack, D.K. Anderson, Mutual diffusion in the liquid system hexane-hexadecane, J. Phys. Chem. 68 (1964) 206-208.

[27] M.V. Kulkarni, G.F. Allen, P.A. Lyons, Diffusion in carbon tetrachloride-cyclohexane solutions, J. Phys. Chem. 69 (1965) 2491-2493.

[28] G.D. Wedlake, F.A.L. Dullien, Interdiffusion and density measurements in some binary liquid mixtures, J. Chem. Eng. Data 19 (1974) 229-235. 
[29] R.L. Rowley, S.C. Yi, D.V. Gubler, J.M. Stoker, Mutual diffusivity, thermal conductivity, and heat of transport in binary liquid mixtures of alkanes in carbon tetrachloride, Fluid Phase Equilibria 36 (1987) 219-233.

[30] R.L. Rowley, S.C. Yi, D.V. Gubler, J.M. Stoker, Mutual diffusivity, thermal conductivity, and heat of transport in binary liquid mixtures of alkanes in chloroform, J. Chem. Eng. Data 33 (1988) 362-366.

[31] W.F. Calus, M.T. Tyn, Temperature and concentration dependence of diffusion coefficient in benzene- $n$-heptane mixtures, J. Chem. Eng. Data 18 (1973) 377-380.

[32] K.R. Harris, C.K.N. Pua, P.J. Dunlop, Mutual and tracer diffusion coefficients and frictional coefficients for the systems benzene-chlorobenzene, benzene- $n$-hexane, and benzene- $n$-heptane at $25^{\circ}, \mathrm{J}$. Phys. Chem. 74 (1970) $3518-3529$.

[33] T.M. Aminabhavi, P. Munk, Diffusion coefficients of some nonideal liquid mixtures, J. Phys. Chem. 84 (1980) 442-446.

[34] L. Rodwin, J.A. Harpst, P.A. Lyons, Diffusion in the system cyclohexane-benzene, J. Phys. Chem. 69 (1965) $2783-2785$.

[35] S.A. Sanni, C.J.D. Fell, H.P. Hutchison, Diffusion coefficients and densities for binary organic liquid mixtures, J. Chem. Eng. Data 16 (1971) 424-427.

[36] D.W. McCall, D.C. Douglass, Diffusion in binary solutions, J. Phys. Chem. 71 (1967) 987-997.

[37] C.M. Kelly, G.B. Wirth, D.K. Anderson, Tracer and mutual diffusivities in the system chloroform-carbon tetrachloride at $25^{\circ}$, J. Phys. Chem. 75 (1971) 3293-3296.

[38] H.T. Cullinan Jr., H.L. Toor, Diffusion in the three-component liquid system acetone-benzene-carbon tetrachloride, J. Phys. Chem. 69 (1965) 3941-3949.

[39] D.K. Anderson, J.R. Hall, A.L. Babb, Mutual diffusion in non-ideal binary liquid mixtures, J. Phys. Chem. 62 (1958) 404-409.

[40] W.M. Melzer, W. Baldauf, H. Knapp, Measurement of diffusivity, viscosity, density and refractivity of eight binary liquid mixtures, Chem. Eng. Progress. 26 (1989) 71-79.

[41] A.Z. Tasic, B.D. Djordjevic, S.P. Serbanovic, D.K. Grozdanic, Diffusion coefficients for the liquid system acetonecyclohexane at 298.15 K, J. Chem. Eng. Data 26 (1981) 118-120.

[42] D.K. Anderson, A.L. Babb, Mutual diffusion in non-ideal liquid mixtures: III. Methyl ethyl ketone-carbon tetrachloride and acetic acid-carbon tetrachloride, J. Phys. Chem. 66 (1962) 899-901.

[43] V. Sanchez, M. Clifton, Mutual diffusion in binary mixtures of carbon tetrachloride and alcohols at $20^{\circ} \mathrm{C}$, J. Chem. Eng. Data 23 (1978) 209-212.

[44] G.H. Shroff, L.W. Shemilt, Liquid diffusivities for the system n-propanol-toluene, J. Chem. Eng. Data 11 (1966) $183-185$.

[45] D.K. Anderson, A.L. Babb, Mutual diffusion in non-ideal liquid mixtures: II. Diethyl ether-chloroform, J. Phys. Chem. 65 (1961) 1281-1283.

[46] P.C. Carman, Self-diffusion and interdiffusion in complex-forming binary systems, J. Phys. Chem. 71 (1967) $2565-2573$

[47] M.T. Tyn, W.F. Calus, Temperature and concentration dependence of mutual diffusion coefficients of some binary liquid systems, J. Chem. Eng. Data 20 (1975) 310-316.

[48] V. Vitagliano, A. Zagari, R. Sartorio, Diffusion and viscosity in $\mathrm{CHCl}_{3}-\mathrm{CH}_{3} \mathrm{COOH}$ system at $25^{\circ} \mathrm{C}$, J. Chem. Eng. Data 18 (1973) 370-372.

[49] Z.J. Derlacki, A.J. Easteal, A.V.J. Edge, L.A. Woolf, Z. Roksandic, Diffusion coefficients of methanol and water and the mutual diffusion coefficient in methanol-water solutions at 278 and $298 \mathrm{~K}$, J. Phys. Chem. 89 (1985) 5318-5322.

[50] Y.E. Lee, S.F.Y. Li, Binary diffusion coefficients of the methanol/water system in the temperature range $30-40^{\circ} \mathrm{C}, \mathrm{J}$. Chem. Eng. Data 36 (1991) 240-243.

[51] C.R. Wilke, P.R. Chang, Correlations of diffusion coefficients in dilute solutions, AIChE J. 1 (1955) 264-270.

[52] M.T. Tyn, W.F. Calus, Diffusion coefficients in dilute binary liquid mixtures, J. Chem. Eng. Data 20 (1975) 106-109.

[53] K. Nakanishi, Prediction of diffusion coefficient of nonelectrolytes in dilute solution based on generalized HammondStokes plot, Ind. Eng. Chem. Fundam. 17 (1978) 253-256. 